\title{
Kd o portugues dk gnt??? :-D \\ o blog, a gramática e o professor
}

\author{
Eliana Maria Severino Donaio Ruiz \\ USF - Universidade São Francisco - Itatiba - SP
}

\begin{abstract}
Com o objetivo de subsidiar a prática de análise lingüística por professores de língua portuguesa, este trabalho busca compreender, sob a ótica sociointeracionista, como se dá a sistematização dos recursos lingüísticos na construção de um gênero textual emergente: o blog. O corpus é formado por textos coletados de diários on-line disponíveis na internet no mês de março de 2004. Por ser própria de um ambiente marcado dentro do universo virtual da internet, e por ser de apropriação de um grupo predominantemente jovem, a linguagem do blog mostra-se na fronteira entre a fala e a escrita, apresentando marcas que refletem o quanto as escolhas gramaticais, lexicais e semânticas do internauta são motivadas pelo contexto situacional em que é produzida. O entendimento desse processo pode auxiliar o professor de língua a tomar posição diante das interferências da escrita virtual na escrita escolar de seus alunos.
\end{abstract}

In order to subsidize the practice of linguistic analysis of Portuguese language teachers, from the sociointeractionism viewpoint, this study aims at analyzing how the linguistic resources are systematized in the construction of an emergent textual genre, the blog. The data are texts collected from on-line diaries available on the Internet in March 2004. As the blog language pertains to a typically virtual environment as well as to a predominantly youth group, it is placed between speech and writing, and presents characteristics that reflect how the grammatical, lexical and semantic choices of the Internet browser are motivated by the situational contexts in which such a language is produced. The understanding of this process can help the teacher face virtual writing interferences when dealing with student writings.

Este trabalho busca compreender que recursos lingüísticos são usados por adolescentes na construção do gênero blog, com o objetivo de subsidiar a prática pedagógica de professores de língua portuguesa

\footnotetext{
* Uma primeira versão deste artigo foi submetida à avaliação pela comissão organizadora da FIRST REGIONAL LATIN-AMERICAN SYSTEMIC FUNCTIONAL LINGUISTIC CONFERENCE - Facultad de Filosofía y Letras, UNCuyo, 8-10 abril - Mendoza (Argentina).
} 
do ensino fundamental, preocupados com a possível interferência da linguagem de contextos virtuais em textos escolares. Vamos inicialmente delinear o quadro teórico em que nos inserimos, para, em seguida, fazer uma breve apresentação desse gênero, analisando a função de algumas categorias gramaticais que lhe são típicas e refletindo sobre a conduta do professor de língua diante dessa realidade.

\section{Pressupostos teóricos}

Inserimo-nos numa perspectiva enunciativa, na qual o objeto de estudo é a linguagem, concebida como forma de interação entre sujeitos sócio-historicamente situados (BAKHTIN, 1997), e não a lingua, entendida como sistema estável de regras isolado do contexto em que é produzido. Distanciando-nos, pois, da corrente formalista do pensamento lingüístico, aproximamo-nos do paradigma funcional, ou corrente funcionalista, que "se preocupa com as relações (ou funções) entre a língua como um todo e as diversas modalidades de interação social" (NEVES, 1997, p. 41), "[incluindo em sua análise] toda a situação comunicativa: o propósito do evento de fala, seus participantes e seu contexto discursivo". ${ }^{1}$ Para as escolas funcionalistas, torna-se essencial pensar nos usos de linguagem efetivamente realizados pelos falantes, considerando-se os objetivos e os propósitos que esperam realizar. Segundo Halliday (1985, p. 3), que entende que "a organização de toda linguagem natural deve ser explicada em termos de uma teoria funcional", torna-se necessário admitir as funções como uma "propriedade fundamental da própria linguagem, alguma coisa que é básica para a evolução do sistema semântico".

Tal visão de linguagem é assumida por diferentes domínios da lingüística atual, além de ser adotada pelos Parâmetros Curriculares Nacionais $(\mathrm{PCN})^{2}$ e por livros didáticos de língua portuguesa avaliados positivamente pelo Plano Nacional do Livro Didático (PNLD). ${ }^{3}$

Dada a enorme repercussão das contribuições de Bakhtin (1997) aos estudos lingüísticos, para quem a linguagem só se realiza por meio de gêneros textuais, as diretrizes metodológicas para o ensino de língua

\footnotetext{
${ }^{1}$ NEVES. A Gramática Funcional, p. 3.

${ }^{2}$ BRASIL. Parâmetros curriculares nacionais de lingua portuguesa $-1^{\circ}$. e $2^{o}$. ciclos.
}

${ }^{3}$ BRASIL. Guia dos livros didáticos: $5^{a}$. a 8 $8^{a}$. séries. 
propostas pelos PCN do Ensino Fundamental II, de base sóciointeracionista, tomam o gênero como objeto de ensino e o texto como unidade de ensino.

Os gêneros textuais também têm sido objeto de inúmeras descrições na última década, com diversidade de enfoques que procuram atender aos mais variados aportes teóricos. Definidos como "tipos relativamente estáveis de enunciados" " elaborados por cada esfera de utilização da língua, os gêneros são construídos sócio-historicamente, assumindo características temáticas, composicionais e estilísticas próprias, por estarem relacionados diretamente a diferentes situações sociais.

\section{Gêneros textuais da internet}

Não há dúvida de que o computador mudou nossa maneira de ler, construir e interpretar textos. O hipertexto digital, que integra linguagem escrita, imagem, voz e música - apresentando-os conjunta e interativamente e de modo não-linear -, gera para o leitor a possibilidade de acessar e absorver informações multi-sensorial e sinestesicamente, num infinito processo de hiper-intextualidade (XAVIER, 2003).

Esse impacto das tecnologias digitais tem feito surgir várias e versáteis formas de textualização: os gêneros internéticos, que, segundo Marcuschi (2002), ${ }^{5}$ não apenas simulam alguns gêneros textuais preexistentes, como realizam efetivamente a interação nesse meio. ${ }^{6}$

Em trabalho sobre a linguagem na construção de hipertextos e a escrita nas salas de bate-papo em meio virtual, Braga (1999) já apontava incorporação de traços da oralidade atrelada aos recursos expressivos do texto eletrônico no gênero chat, expandindo os recursos

\footnotetext{
${ }^{4}$ Cf. BAKHTIN. Estética da Criação Verbal.

${ }^{5}$ Nova versão desse texto pode ser encontrada em MARCUSCHI, L. A. Gêneros textuais emergentes no contexto da tecnologia digital. In: MARCUSCHI, L. A.; XAVIER, A. C. dos S. (Org.). Hipertexto e gêneros digitais: novas formas de construção de sentidos. Rio de Janeiro: Lucerna, 2004. No prelo.

${ }^{6}$ São eles: $e$-mail, bate-papo (virtual em aberto, virtual reservado, ICQ agendado, virtual em salas privadas), entrevista com convidado, aula virtual, vídeo-conferência, lista de discussão, endereço eletrônico).
} 
expressivos desenvolvidos pela escrita convencional. Por serem produzidos num novo formato de escrita, os gêneros em ambientes virtuais desconstroem a oposição tradicional entre a fala e a escrita, aproximando-as, interagindo-as (HALLIDAY, 1996, apud MARCUSCHI, 2002). Em razão de a produção ser, na maioria das vezes, síncrona, essa simultaneidade temporal faz com que se altere a própria noção de autor, de leitor e dos processos de construção do sentido, já que é o tempo real que dá à oralidade em situações autênticas uma característica peculiar.

Muito embora Marcuschi (2002) não mencione o blog em seu trabalho sobre gêneros no contexto da tecnologia digital, trata-se de um gênero textual emergente de grande utilização por usuários de várias categorias, uma vez que há blogs pessoais (individuais ou coletivos) e institucionais. ${ }^{7}$

\section{O blog}

O termo Weblog é derivado da união das palavras inglesas Web (rede) e $\log$ (diário de bordo onde os navegadores registravam eventos de suas viagens). Segundo LISBÔA (2003), a maioria dos blogs tem a função de diário aberto, criado pelos blogueiros para desabafar quando não há amigos por perto, expor idéias, opiniões e críticas ou, ainda, porque se tornou moda em passado recente, servindo hoje para que as pessoas se conheçam melhor e para que aqueles que estão longe fiquem sabendo o que se passa no cotidiano de seu "dono". ${ }^{8}$

A estrutura dos blogsé relativamente padronizada: obedece a uma ordem cronológica inversa da leitura canônica, isto é, os textos mais recentes produzidos pelo(s) proprietário(s) do blog, chamados posts, aparecem no topo da página e os mais antigos no final. Normalmente, o blogueiro adiciona tais posts quase que diariamente, podendo inserir também textos de sua própria autoria, letras de músicas, poemas, ou informações variadas, acompanhadas do registro da data - outra

\footnotetext{
7 Os vínculos entre conhecidos, desconhecidos ou anônimos são pessoais, comunitários, trabalhistas, filantrópicos e outros.

${ }^{8}$ Existe até o Jornal do Blogueiro (www.jornaldoblogueiro.blogger.com.br), endereço onde blogueiros antigos se reúnem para postar notícias da mídia relacionadas ao assunto, além de opiniões sobre temas que lhe são próprios.
} 
semelhança com o antigo diário escrito em cadernos. Também podem estar disponíveis links para outros blogs, julgados interessantes pelo blogueiro, numa espécie de recomendação aos seus leitores - mostrando que autores de blogs são também ávidos leitores do gênero, e que esse entrelaçamento acaba formando uma comunidade muito particular.

Há, por exemplo, um espaço de interlocução numa seção de apresentação (feita de maneira alegre e extrovertida), na qual o escrevente disponibiliza para o leitor informações pessoais como nome (ou nickname $^{9}$ ), idade, procedência geográfica, local de residência e ocupação atuais, além de hobbies e preferências. ${ }^{10}$ Há, ainda, a disponibilização de um e-mail para o leitor - também imaginado como simpático e receptivo a esse tipo de texto -, de quem sempre o blogueiro solicita um contato. Mas, em geral, isso é feito através de uma sessão de guestbook (livro de visitas), onde o visitante preenche um formulário com seus dados pessoais e, em seguida, redige suas opiniões, sugestões e críticas (o que também se dá em tom simpático e educado) e as envia de maneira on-line. ${ }^{11}$

É na pesquisa de Komesu (2001), que discute a escrita proposta nas páginas eletrônicas pessoais da internet, que encontramos uma interessante descrição do gênero blog. Identificando o que pode ser tomado como característico dessa escrita digital, em face de outras práticas de escrita sócio-historicamente já constituídas, ${ }^{12}$ a autora conclui que se trata de uma forma de interação marcada pela função fática $^{13}$ da linguagem, com fórmulas de comunicação mais rituais que informativas. O escrevente projeta uma imagem pessoal (o "herói") que pareça simpática e, desse modo, estabelece, também, a simulação de uma intimidade para alcançar esse objetivo. Tal procedimento, segundo

9 Apelido relacionado à imagem que faz de si ou à relação que pretende estabelecer com o leitor (como "BelleDeJour", "Magno", "Misterioso" etc.).

${ }^{10}$ Como "navegar pela internet", "sair com os amigos", "namorar", "ouvir música", "dançar" etc.

${ }^{11}$ Em alguns casos, a página disponibiliza a opção de visualização de tais visitas e interlocuções por outros leitores.

12 Como as apresentações pessoais em orelhas de livros impressos, as (auto)biografias, as cartas manuscritas e os e-mails.

13 Interpessoal, na visão de Halliday (1985). 
ela, no entanto, mascara a confiscação da palavra ${ }^{14}$ no gênero, onde o escrevente tem o direito de se expressar, desde que seja de um determinado modo, isto é, por meio de alguns recursos da modalidade escrita (como a pontuação, na sua relação com a prosódia, e o uso de maiúsculas), de certas marcas de enunciação (como os pronomes pessoais de primeira e de segunda pessoa), de sinais gráficos específicos (como os emoticons ${ }^{15}$ e as "risadinhas") e de léxico também específico (importado da área da informática).

Supondo, entretanto, ainda haver outros traços característicos dessa linguagem que não foram explorados por Komesu em seu trabalho, julgamos pertinente a pequena investigação que ora fazemos, com o intuito de contribuir um pouco mais com as pesquisas que têm se debruçado sobre as formas híbridas de escrita, constituintes tanto do blog como de outros gêneros digitais.

\section{Marcas gramaticais}

Para os fins desta investigação inicial, foram selecionados ${ }^{16}$ dois blogs individuais (um masculino: BURUNINHO; e um feminino: KA) e dois blogs coletivos femininos (NOIADAS e ARBORETS) - todos de adolescentes com idade entre 13 a 16 anos (estudantes de uma escola particular de Campinas, SP, Brasil) -, além de um blog individual masculino (DISTANTE DO MUNDO REAL) e um blog coletivo feminino (NAUFRAGAS), ambos produzidos por adultos (um estudante de Jornalismo e três mulheres: duas jornalistas e uma advogada), coletados ao acaso num site de busca, em março de 2004. A inclusão destes dois últimos se deu em razão da possibilidade de estabelecermos alguns contrastes interessantes para a compreensão da linguagem do gênero relativamente à variável faixa etária.

Apresentamos, a seguir (ver quadros anexos), uma pequena seleção de exemplos das marcas gramaticais que identificamos como

\footnotetext{
${ }^{14}$ Cf. CORRÊA (1993, apud KOMESU, 2001).

15 Ícones de emoção, também chamados de Smiles ou CARacterETAS. Para lêlos, deve-se inclinar a cabeça para a esquerda.

${ }^{16}$ Agradecemos a Ana Elisa de Arruda Penteado, pela gentil colaboração na coleta dos dados.
} 
características do gênero blog produzido por adolescentes, segundo o pequeno conjunto de amostras coletadas. ${ }^{17}$ Trata-se dos recursos gramaticais utilizados por esses escreventes - como blogueiros, enunciadores privilegiados dos posts dialogais constitutivos do gênero - para obter alguns efeitos de sentido junto aos seus interlocutores. Lembramos que, por entendermos que os recursos lingüísticos utilizados pelos usuários de uma língua servem a propósitos interacionais, a noção de gramática que nos norteia é funcional e não estrutural, no sentido de ter uma autonomia em relação ao processo comunicativo. Dessa forma, entenderemos as marcas gramaticais encontradas nos textos do gênero aqui elegido para análise na sua interrelação com as demais instâncias do processo discursivo em que se colocam seus produtores.

A disposição dos elementos nos quadros procura traçar justamente as correspondências entre os recursos lingüísticos empregados por tais enunciadores e o propósito comunicativo dos mesmos no contexto eletrônico em que se inserem. Os textos encontram-se acompanhados de sua respectiva "tradução" para forma ortográfica padrão do português. Certamente, ao comentarmos os posts retratados nos quadros, ${ }^{18}$ estaremos, de certa forma, dando conta dos demais exemplares do corpus, haja vista a recorrência desse estilo - que poderíamos chamar de coletivo - de comunicação.

A primeira impressão que se tem é a de que a linguagem do chat excursionou para o blog. Tendo em vista que os blogueiros parecem fazer parte de uma comunidade de internautas familiarizada com as ferramentas tecnológicas necessárias para levar a cabo uma interação mediada pela máquina, e se mostrem empenhados em se comunicar quase que diariamente com seus pares, ${ }^{19}$ tudo leva a crer que estejam simplesmente importando para o blog as formas lingüísticas típicas do discurso do chat. Fazem, pois, uso da forma de linguagem que consideram politicamente correta, ou autorizada, para interagir nesse meio. Muito

\footnotetext{
${ }^{17}$ Usaremos números para identificar os posts e abreviações para indicar a que blog pertencem (por exemplo, BR1 significa "post 1 do blog BURUNINHO").

${ }^{18}$ Por questões de espaço, tivemos de limitar a apresentação dos posts coletados a um número bastante reduzido de evidências.

${ }^{19} \mathrm{O}$ que se deduz pela estreiteza das datas de postagem das mensagens.
} 
embora a troca de mensagens no blog (estruturada pelo par post do blogueiro / post do visitante via guestbook ou comentário) não se dê em tempo real, como nas salas de bate-papo da internet, onde o formato de diálogo carrega consigo a estrutura em turnos (aproximandose, nesse sentido, mais da linguagem própria dos e-mails), a forma que assume o tipo de interlocução nessas páginas pessoais lembra, como no chat, a conversação. Isso porque, devido às especificidades do meio em que os interlocutores estão em contato, eles precisam escrever suas falas, numa espécie de "conversação com expressão gráfica" (Cf. BARROS, 2000 apud BERNARDES e VIEIRA, [2002?]).

Assim, paradoxalmente, essa "paciente" conversa por escrito, assíncrona (descendente da velha carta manuscrita remetida por correio), carrega consigo algumas marcas da rapidez própria do texto conversacional da fala cotidiana, síncrono pela própria natureza fenômeno também característico do chat (Cf. BERNARDES e VIEIRA, [2002?]). Por isso, os recursos mais empregados pelos estudantes nos posts interativos de seus blogs são aqueles que lhes possibilitam falar por escrito através do computador, de modo que lingüisticamente o discurso se mostre marcado por formas que tanto oralizam como agilizam a escrita, reconfigurando-a.

A exemplo dos chats (onde o interlocutor está na linha e espera que o turno do outro aconteça de imediato), tal agilização se dá por meio de uma aceleração do processo de digitação do texto, numa espécie de telegrafia levada às últimas conseqüências, onde a velocidade da comunicação se impõe de tal modo que a formatação tradicional caminha em direção a uma escrita primitiva, fazendo-nos recordar muitas das formas silábicas apresentadas por crianças em fase inicial de aquisição da modalidade. Assim, como tentativa de agilização da escrita, ocorrem em grande número:

- supressões de acentos gráficos (às vezes recuperados pela inserção alternativa de $b$ final, em caso de monossílabos tônicos ou de oxítonas, ou às vezes mantidos por inconsistência da rápida digitação pelo escrevente);

- supressões de sinais de pontuação (como o ponto final que marca as fronteiras oracionais);

- supressões de certas vogais de palavras (o que, contudo, não impede que sejam perfeitamente inferidas pelo leitor); 
- abreviações de palavras (à imagem e semelhança da escrita silábica por parte de aprendizes da modalidade) e

- substituições de palavras/expressões por símbolos e/ou algarismos.

Já como estratégia de oralização da escrita, nota-se a presença de:

- elementos típicos da conversação (como os marcadores conversacionais, as interjeições, o alongamento de vogais ou de consoantes);

- o reforço da pontuação expressiva (na tentativa de simular entonação);

- o uso de maiúsculas (para dar ênfase);

- o emprego de emoticons (no esforço de registrar sentimentos do enunciador) e

- a tentativa de criação de um alfabeto fonético (ou código escrito que se aproxime de uma escrita fonética).

Além desses dois grandes recursos, são ainda utilizadas:

- formas que denotam uma preocupação do usuário em configurar um estilo próprio (a fim de personalizar sua escrita, a ponto de ser reconhecido visualmente - tal como ocorre com a caligrafia no uso de letra cursiva);

- gírias (que pretendem traçar uma demarcação do território social em que se inserem o blogueiro e seus pares);

- empréstimos do inglês (típicos do léxico próprio do campo semântico da internet);

- formas do registro informal (a fim de criar intimidade com o interlocutor);

- formas canônicas da escrita (que permitem que os leitores estabeleçam minimamente uma coerência ao texto);

- dêiticos (que fazem referência aos demais textos postados no blog, ou ao $e$-universo) e

- pronomes de primeira e de segunda pessoa (que constituem as evidências mais fortes do caráter dialógico desses posts).

Parece-nos também válido ressaltar que, embora nossos dados não nos possibilitem afirmar categoricamente - ficando isso para ser investigado em momento oportuno -, essa formatação da comunicação está restrita a esse grupo específico de adolescentes, ou a grupos fechados, 
com necessidade de auto-afirmação. Talvez, à medida que os usuários vão mudando de faixa etária, vão igualmente mudando seu foco de interesse, tanto em termos interacionais quanto em termos temáticos, o que deve, evidentemente, se refletir na linguagem. Além disso, conforme vá se acentuando um maior domínio da língua materna por parte de tais estudantes, provavelmente mais flexíveis se mostrarão na utilização das diversas formas de linguagem à sua disposição, para se comunicarem nos mais diferentes gêneros textuais. Haverá, conseqüentemente, uma consciência maior quanto à dispensa da utilização, em seus diários pessoais, de uma gramática típica de interações síncronas, como é o caso do chat - onde a agilização da escrita é constitutiva do gênero -, mas certamente não do blog, característico pela assincronicidade da interação.

Finalmente, há que se notar o enorme esvaziamento temático desses textos dialogais que, por estarem mais a serviço de manter o vínculo entre os componentes da comunidade discursiva a que pertencem seus produtores, nada trazem de interessante para quem não faz parte da "tribo". A impressão que fica é a de que seus autores não têm assunto a tratar ou, se têm, delegam essa tarefa para as poesias, fotos, letras de músicas, sons e imagens - demais textos, gêneros e linguagens - que compõem o hipertexto em que se inserem. Parecem, mesmo, tais posts, quase que desprovidos da função de referência - ideacional ou experiencial no dizer de Halliday (1985) -, já que prevalece a todo momento a função interpessoal da linguagem, na conhecida intenção de meramente garantir o contato entre os interlocutores, mantendo-o aceso, vivo.

Contrastivamente, observa-se que na linguagem dos adultos esses recursos desaparecem, para, entretanto, dar lugar a outros, como é o caso do post a respeito do filme "Paixão de Cristo", onde o blogueiro, estudante de Jornalismo, recupera com eficiência a linguagem da área, numa clara intenção de tornar seu blog pessoal (DISTANTE DO MUNDO REAL) um interessante espaço para o exercício da reflexão, à imagem e semelhança dos suportes de textos midiáticos impressos que conhecemos. Ou, então, como ocorre no texto de NAUFRAGAS, onde se vê um certo cuidado da blogueira para salvaguardar sua própria imagem perante o leitor, optando por usar melda, em vez de merda - um termo censurável do seu ponto de vista. 


\section{Implicações no ensino}

Como pudemos ver, a comunicação em meio eletrônico é um atestado vivo de que a relação oralidade-escrita vem se transformando, sendo cada vez mais entendida como um continuum. As fronteiras entre o que antes pareciam ser dois pólos vêm se desvanecendo, tornando-se permeáveis nos chamados gêneros mistos ou híbridos, sob o ponto de vista da modalidade (Cf. MARCUSCHI, 2002), como é o caso do blog. A $e$-escrita, desde que surgiu, numa tentativa de transcrever a fala, vem sofrendo alterações em seu processo de visualização da oralidade. Pode-se mesmo afirmar que temos, hoje, um novo conceito de texto escrito, que vem se concretizando nas telas do computador, nos mais variados gêneros digitais. Na linguagem MIRCada, a inclusão de imagens (que não mais funcionam como meras ilustrações, mas constituem partes integrantes daquilo que se deseja comunicar) e de sons (que já são de fácil armazenagem e recuperação), enfim, de recursos gráficos e sonoros de toda ordem, gerando um processo de infinita intertextualidade, é o diferencial na leitura que fazemos dos hipertextos, dos quais o blog é apenas uma categoria.

Sobre a linguagem típica desse gênero, o bloguês, ${ }^{20}$ foco deste trabalho, pudemos observar, como Marcuschi (2002, p. 5), que ela se faz marcar, como forma de comunicação digital, por "uma pontuação minimalista, uma ortografia um tanto bizarra, abundância de siglas e abreviações nada convencionais, estruturas frasais pouco ortodoxas e uma escrita semi-alfabética", numa evidente tentativa de oralização da escrita. Ou seja, trata-se de um texto falado por escrito, carregado de gírias e empréstimos lingüísticos. São esses os traços que configuram essa "língua de bárbaros" que, como tudo que inova, rompendo cânones até então vigentes, não pode deixar de incomodar a muitos, tanto em contexto escolar como fora dele.

Entretanto, antes de os puristas lamentarem o "fim da língua portuguesa", devem estar atentos a que, conforme foi dito, tais características configuram aquilo que é constitucional no gênero, uma vez que só funcionam nesse tipo de enunciado - se quisermos usar um termo bakhtiniano.

\footnotetext{
${ }^{20}$ Tomo o termo emprestado de LISBÔA (2003).
} 
Uma preocupação, porém, sem sombra de dúvida, se assoma: como fica, então, a situação do aluno que escreve em sala de aula? Será que há o risco de essa linguagem ser transplantada para a escrita dos gêneros escolares? Como o professor deve agir diante de tal realidade?

Mesmo não se podendo precisar ainda, com exatidão, o grau de interferência do bloguês na escrita escolar - e de outras linguagens moradoras do meio eletrônico -, o que nos parece certo é que, assim como não podemos represar com os dedos esse rio que é a língua em constante processo de mudança, não há como conter essa realidade que vem explodindo nas telas dos computadores de nossos adolescentes. Ela não depende de quem não se reconhece como seu usuário, tampouco dos guardiões do idioma que, em geral, se mostram conservadores e a encaram com preconceito. Quem usa essa linguagem tem plena noção de que escreve do jeito que escreve porque está num ambiente demarcado, onde, mais importante que violar a ortografia ou enxertar emoticons para falar por escrito, é produzir graça e manter o estilo jovial de modo informal, amistoso e lúdico. E isso só ocorre porque o avanço tecnológico tornou possível a comunicação à distância em tempo real intermediada por computador acoplado a uma linha telefônica.

Se antes nossos adolescentes não escreviam, ou escreviam apenas em contexto escolar, numa linguagem o tempo todo policiada, agora eles não só passaram a escrever mais, ${ }^{21}$ como descobriram que podem fazê-lo como quiserem, porque longe dos olhos da censura, usando o registro coloquial com mais liberdade ainda do que a que lhes é própria.

Quanto à influência dessa realidade lingüística nos textos escolares, ${ }^{22}$ talvez a oralidade esteja hoje mais presente em redações de alunos praticantes dessa forma de interação a distância, com sua fluência característica, não importando se advinda dos blogs, das salas

\footnotetext{
${ }^{21}$ Tal fato pode ser atestado por qualquer pessoa que more ou conviva com um adolescente usuário de internet.

${ }^{22}$ Esse fato, embora não comprovado cientificamente, foi aventado por professores de Língua Portuguesa do ensino fundamental e médio que participaram da primeira fase do programa de educação continuada "Teia do Saber", patrocinado pela Secretaria de Educação do Estado de São Paulo e oferecido, no último trimestre de 2003, pela Universidade Estadual de Campinas, a professores da rede pública da região de Campinas - do qual participamos na condição de docente responsável por uma das turmas (Cf. SIGNORINI et al., no prelo).
} 
de bate-papo ou dos e-mails - hipótese que, evidentemente, merece ser testada. E mais, se essa presença trouxer a reboque traços da linguagem mircada, valeria a pena investigar, também, se trata-se apenas de uma mera expressão de rebeldia (mais fácil de o professor contornar), ou se é sinal de uma aquisição da escrita ainda em processamento, pois aí o trabalho do professor demandaria um cuidado metodológico maior.

O que propomos para os casos em que essa influência já seja realidade é que, ao invés de o professor se limitar unicamente a fazer correções de caráter resolutivo (Cf. RUIZ, 2001; RUIZ e PENTEADO, 2004) nas interferências escritas que faz nos textos de seus alunos, seria mais produtivo que ele investisse, por exemplo, num trabalho de análise lingüística dos gêneros textuais envolvidos, mostrando-lhes que a linguagem presente nos posts interativos dos blogs, embora possa parecer subvertida, é, na verdade, fruto também de uma intensa reflexão lingüística por parte dos usuários do gênero, em seu trabalho de abreviar, oralizar, alongar ou criptografar ${ }^{22}$ palavras. Ao fazer isso, o professor poderia, ainda, mostrar como e por que, a despeito da interessante criatividade envolvida nesse processo, o produtor de uma redação escolar, freqüentador de $e$-contextos, precisa estar atento às formas lingüísticas autorizadas em cada caso.

Muito embora à primeira vista não pareça, sobretudo para quem não faz parte da comunidade dos beavy users, ${ }^{24}$ a sistematização da língua no bloguês também existe, porém de uma forma mais maleável que aquela prevista pelo registro coloquial padrão, ou pela gramática normativa tradicional, dado o caráter mais democrático do gênero, ao permitir que convivam pacificamente formas variantes em vários níveis (como ocorre com gnt ou genti - "gente" - por exemplo). Exatamente pela função do gênero ser a interação com outros usuários de uma comunidade restrita, permanece, contudo, tal qual nas demais formas de linguagem, a necessidade de se fazer entender pelos leitores. Nesse sentido, o usuário que pretende inovar precisa, entretanto, estar sempre atento às

\footnotetext{
${ }^{23}$ O recurso da criptografia é usado especialmente para grafar nomes próprios, na tentativa de criar uma identidade "blogueira" pessoal dos usuários. São usadas letras do alfabeto grego ou cirílico, assim como símbolos (por exemplo, @, (c), (,$\&)$ e outras tantas que se assemelhem a letras de nosso alfabeto.

${ }^{24}$ Usuários contumazes, que se conectam à internet todos os dias.
} 
restrições estruturais impostas pelo próprio sistema da língua, sob pena de ficar falando sozinho, ou espraiar palavras incoerentes ao vento.

Uma pergunta fica, contudo, como proposta para reflexão: até que ponto, escrevendo-se em bloguês ou numa hiperlinguagem que simule a conversação face-a-face, pode-se mexer nas estruturas da língua antes que ela se descaracterize de tal forma que impeça a comunicação?

Seja como for, por se tratar de um gênero emergente, o blog e todos os demais gêneros textuais que configuram os meios eletrônicos de comunicação carregam em seu bojo uma linguagem em transformação ${ }^{25}$ - reflexo da revolução nos modos de interagir hiperlingüisticamente -, sobre a qual qualquer investigação que se faça, em face da constante evolução tecnológica onde tal linguagem é gestada, será sempre provisória, porque inegavelmente sujeita à célere ação do tempo.

\section{Referências}

ARBORETS. Disponível em http://www.arborets.blogger.com.br/. Acesso em 26 de março de 2004.

BAKHTIN, M. Estética da Criação Verbal. 2. ed. São Paulo: Martins Fontes, 1997. $421 \mathrm{p}$.

BARROS, D. L. P. de. Entre a fala e a escrita: algumas reflexões sobre as posições intermediárias. In: PRETI, D. (Org.). Fala e escrita em questão. São Paulo: Humanitas, FFLCH, USP, 2000.

BERNARDES, A. S.; VIEIRA, P. M. T. No discurso produzido em salas de batepapo na internet, a descoberta de um espaço de produção de linguagem. [2002?]. Mimeografado.

BRAGA, D. B. A constituição híbrida da escrita na internet: a linguagem nas salas de bate-papo e na construção dos hipertextos. In: Leitura: teoria e prática. Campinas, SP: Mercado de Letras, n. 18, 1999. p. 23-29.

BRASIL. Ministério da Educação e do Desporto. Parâmetros curriculares nacionais de lingua portuguesa - 1․ e 2º ciclos. Brasília: Secretaria da Educação Fundamental, 1997.

\footnotetext{
${ }^{25}$ Ainda "em estado meio selvagem e indomado sob o ponto de vista lingüístico e organizacional, segundo Crystal (2001, apud MARCUSCHI, 2002, p. 5).
} 
BRASIL. Guia dos livros didáticos: 5a a a $8^{a}$. séries. Brasília: Ministério da Educação, 2003.

BURUNINHO. Disponível em http://www.buruninho.blogger.com.br/. Acesso em 26 de março de 2004.

CRYSTAL, D. Language and the Internet. Cambridge: Cambridge University Press, 2001.

DISTANTE DO MUNDO REAL. Disponível em http://www.pinblogger. weblogger.terra.com.br/. Acesso em 02 de abril de 2004.

HALLIDAY, M. A. K. An introduction to functional grammar. Londres: Edward Arnold, 1985.

HALLIDAY, M. A. K. Literacy and lingguistics: a functional perspective. In: HASAN, R.; WILLIAMS, G. (Org.). Literacy in society. London/New York: Longman, 1996. p. 1339-1376.

KA. Disponível em http://www.ka_blog2.blogger.com.br/. Acesso em 26 de março de 2004.

KOMESU, F. C. A escrita das páginas eletrônicas pessoais da internet: a relação autor-herói/leitor. 2001. 131f. Dissertação (Mestrado em Lingüística) - IEL-Unicamp.

LISBÔA, R. qm entende essa =P?. Folha de S. Paulo, São Paulo, 1 set. 2003. Suplemento Folhateen, p. 1.

MARCUSCHI, L. A. Gêneros textuais emergentes e atividades lingüísticas no contexto da tecnologia digital. In: Anais... GEL - Grupo de Estudos Lingüísticos do Estado de São Paulo, USP - Universidade de São Paulo, 23-25, mai., 2002.

MARCUSCHI, L. A. Gêneros textuais emergentes no contexto da tecnologia digital. In: MARCUSCHI, L. A.; XAVIER, A. C. dos S. (Org.). Hipertexto e gêneros digitais: novas formas de construção de sentidos. Rio de Janeiro: Lucerna, 2004. (No prelo).

NAUFRAGAS. Disponível em http://naufragas.blog.uol.com.br/. Acesso em 02 de abril de 2004.

NEVES, M. H. de M. A Gramática Funcional. São Paulo: Martins Fontes, 1997. $160 \mathrm{p}$.

NOIADAS. Disponível em http://www.noiadas4e.weblogger.terra.com.br/. Acesso em 26 de março de 2004. 
PRIMERA CONFERENCIA REGIONAL LATINO-AMERICANA DE LINGÜÍSTICA SISTÊMICO-FUNCIONAL. 2004. Mendoza. La Lingüística SistêmicoFuncional, la Lengua y la Educación. Evento anual realizado pela Universidad Nacional de Cuyo. 8-10 abril.

RUIZ, E. M. S. D. Como se corrige redação na escola. Campinas: Mercado de Letras, 2001. 247 p. (Coleção Idéias sobre Linguagem).

RUIZ, E. M. S. D.; PENTEADO, A. E. de A. Os instrumentos de avaliação do professor. In: SIGNORINI, I. et al. Metodologias de ensino de lingua portuguesa no Ciclo II do Ensino Fundamental. Teia do Saber. Pró-Reitoria de Extensão/Unicamp/SEE, 2004. No prelo.

SIGNORINI, I. et al. Metodologias de ensino de lingua portuguesa no Ciclo II do Ensino Fundamental. Teia do Saber. Pró-Reitoria de Extensão/ Unicamp/SEE, 2004. No prelo.

XAVIER, A. C. Hipertexto e intertextualidade. In: MORATO, E.; BENTES, A. C.; LIMA, M. L. C. (Org.). Cadernos de Estudos Lingüísticos, 44. Campinas, SP: IEL-Unicamp, p. 281-290, 2003. 


\begin{tabular}{|c|c|c|c|c|c|}
\hline POST & Texto & $\begin{array}{l}\text { "Tradução " P/ o } \\
\text { Português } \\
\text { Padrão escrito }\end{array}$ & Evidências & $\begin{array}{l}\text { Recursos } \\
\text { Gramaticais }\end{array}$ & $\begin{array}{l}\text { Propósito } \\
\text { Comunicativo }\end{array}$ \\
\hline BU 2 & $\begin{array}{l}\text { Bom, só passei p/ } \\
\text { deixar } 4 \text { recados: } \\
\text { 1ํ Vlw Bia por ter } \\
\text { vindo no me blog, } \\
\text { ja q ninguem entra!!! } \\
2^{\circ} \text { To desanimado de } \\
\text { posta sempre q } \\
\text { posto ngm comenta } \\
\text { dps dizem q eu num } \\
\text { posto } \\
3^{\circ} \text { Provavelmente eu } \\
\text { naum post no meio } \\
\text { do Carnaval, mas se } \\
\text { eu curtir mt dai eu } \\
\text { entro na net } \\
4^{\circ} \text { P/ kem num eh } \\
\text { do +qd+ e kiser ter } \\
\text { galera p/ andar no } \\
\text { carnaval da Avenida } \\
\text { entra em contato } \\
\text { cmg, meu tel tah ai } \\
\text { do lado. Postado por } \\
\text { ßü®üN }{ }^{\circ} 2 / 19 / 2004\end{array}$ & $\begin{array}{l}\text { Bom, só passei para } \\
\text { deixar } 4 \text { recados: } \\
1^{\text {o }} \text { Valeu, Bia, por ter } \\
\text { vindo no meu blog, já } \\
\text { que ninguém entra! } \\
2^{\circ} \text { Estou desanimado } \\
\text { de postar. Sempre que } \\
\text { posto ninguém co- } \\
\text { menta, depois dizem } \\
\text { que eu não posto. } \\
3^{\circ} \text { Provavelmente eu } \\
\text { não posto no meio } \\
\text { do Carnaval, mas se } \\
\text { eu curtir muito daí } \\
\text { eu entro na internet. } \\
4^{\circ} \text { Pra quem não é do } \\
\text { "mais que demais" e } \\
\text { quiser ter galera para } \\
\text { andar no carnaval da } \\
\text { Avenida, entra em } \\
\text { contato comigo, meu } \\
\text { telefone está aí do } \\
\text { lado. Postado por } \\
\text { Bruno } 19 / 02 / 2004\end{array}$ & $\begin{array}{l}\text { - } \text { Bom } \\
\text { - to / posta } \\
\text { - } ! ! \\
\text { - vlw } \\
\text { - kem / kiser } \\
\text { - naum } \\
\text { - ninguem/ai } \\
\text { - tah / ja / to / eh } \\
\text { - cmg / q /mt / ngm / } \\
\text { post / tel } \\
\text { - me } \\
\text { - }+ \text { qd+ } \\
\text { - } 4 \text { - ..comenta dps... } \\
\text { - passei / vindo / } \\
\text { entra / ai do lado }\end{array}$ & $\begin{array}{l}\text { - } \text { - Farcador conversacional } \\
\text { informas reduzidas do registro } \\
\text { - Tentativa de reforço da } \\
\text { entonação } \\
\text { - Substituição de u por w (valeu) } \\
\text { - Substituição de qu por k } \\
\text { (quem/quiser) } \\
\text { - Substituição de ão por aum (não) } \\
\text { - Supressão do acento agudo } \\
\text { em oxítona (ninguém / aí) } \\
\text { - Supressão do acento agudo } \\
\text { em monossílabo tônico (tá: forma } \\
\text { reduzida de está/já/tô: forma } \\
\text { reduzida de estou/é) } \\
\text { - Abreviação convencionada } \\
\text { (comigo / que/muito / } \\
\text { ninguém posto/telefone) } \\
\text { - Abreviação (meu) ou erro } \\
\text { de digitação? } \\
\text { - Símbolo (+) } \\
\text { - Algarismo (quatro) } \\
\text { - Supressão da pontuação } \\
\text { em limite oracional } \\
\text { (... comenta. Depois...) } \\
\text { - Dêitico } \\
\text { - Gíria Empréstimo do inglês } \\
\text { (léxico técnico) }\end{array}$ & $\begin{array}{l}\text { - Agilização da } \\
\text { digitação } \\
\text { - Demarcação de } \\
\text { território lingüístico }\end{array}$ \\
\hline
\end{tabular}




\begin{tabular}{|c|c|c|c|c|c|}
\hline KA 1 & $\begin{array}{l}\text { Terça-feira, Fevereiro } \\
24,2004] \\
\text { Nusssssssss.... MÓ } \\
\text { ABANDONADU ISSU } \\
\text { AKI =P } \\
\text { haushUHUAH } \\
\text { SUHuhaush } \\
\text { eh neh!! } \\
\text { CarnA! Tem q } \\
\text { aproveitáááá! } \\
\text { HuehuhuHUHAUSH } \\
\text { Uhuahsu } \\
\text { Eu só vim aki coloká } \\
\text { uns blink na net pa } \\
\text { pode linká nu otro } \\
\text { Blog! Dps eu do um } \\
\text { trato geral okz?! } \\
\text { HAUSHUhas } \\
\text { por *Kä zz!nHä* * } \\
\text { 12:10 PM }\end{array}$ & $\begin{array}{l}\text { terça-feira, } 24 \text { de } \\
\text { fevereiro de } 2004 . \\
\text { Nossa, está muito } \\
\text { abandonado isso aqui } \\
\text { (risos) É, né! } \\
\text { Carnaval! Tem que } \\
\text { aproveitar (risos). } \\
\text { Eu só vim aqui } \\
\text { colocar uns "blink" } \\
\text { na internet para } \\
\text { poder linkar no outro } \\
\text { Blog! Depois eu dou } \\
\text { um trato geral, OK? } \\
\text { (risos) } \\
\text { Por Ka, } 12 \mathrm{~h} 10 \text { PM. }\end{array}$ & $\begin{array}{l}\text { - Nusssssssss } \\
\text { - ISSU AKI / coloká } \\
\text { / linká / nu otro / } \\
\text { aproveitááááa } \\
\text { - haushUHUA } \\
\text { HSUHuhaush / } \\
\text { HuehuhuHUHAUSH } \\
\text { Uhuahsu / } \\
\text { HAUSHUhas } \\
\text { - =P } \\
\text { - eh / neh } \\
\text { - pa pode linká } \\
\text { - pode } \\
\text { - q / CarnA / Dps } \\
\text { - vim aki / na net } \\
\text { - do um trato geral } \\
\text { / MÓ ABANDONADU } \\
\text { - blink / net / Blog / } \\
\text { okz }\end{array}$ & $\begin{array}{l}\text { - Repetição de consoante (Nossa!) } \\
\text { - Simulação de transcrição fonética } \\
\text { (isso aqui / colocar / lincar / } \\
\text { num outro / aproveitar) } \\
\text { - Risadinha } \\
\text { - Emoticon } \\
\text { - Supressão de acento final em } \\
\text { monossílabo tônico é / né) } \\
\text { - Forma reduzida do registro } \\
\text { informal (para poder lincar) } \\
\text { - Supressão de r final em } \\
\text { oxítona (poder) } \\
\text { - Abreviação convencionada } \\
\text { (que / Carnaval / depois) } \\
\text { - Dêitico } \\
\text { - Gíria } \\
\text { - Empréstimo do inglês }\end{array}$ & $\begin{array}{l}\text { - Demarcação de } \\
\text { território lingüístico }\end{array}$ \\
\hline
\end{tabular}




\begin{tabular}{|l|l|}
\hline POST & \multicolumn{1}{c|}{ TEXTO } \\
\hline DI 1 & $\begin{array}{l}\text { sábado, 20 de março de 2004 } \\
\text { O martírio de Jesus } \\
\text { [foto] } \\
\text { O grande diferencial do filme "A Paixão de Cristo" (The Passion of the } \\
\text { Christ), de Mel Gibson, para as produções anteriores sobre a morte de } \\
\text { Jesus, é a violência excessiva. Nunca o cinema retratou com tanto realismo } \\
\text { as cenas do sofrimento de Jesus nas suas últimas 12 horas de vida. } \\
\text { Segundo o material de divulgação do filme, esse é mesmo o propósito } \\
\text { do diretor: "expressar realmente a enormidade do sacrifício, assim como } \\
\text { seu horror". } \\
\text { [... Assisti ao filme nesta sexta-feira e presenciei as reações do público. } \\
\text { Enquanto Jesus Cristo é flagelado, o público reage de formas distintas às } \\
\text { cenas brutais. Algumas pessoas choram, outras preferem desviar } \\
\text { momentaneamente os olhos da tela. Porém, é impossível não se emocionar. }\end{array}$ \\
\hline \multirow{1}{*}{ NA 1 } & $\begin{array}{l}\text { O sentimento que deve predominar na cabeça de cada espectador após o } \\
\text { filme é o desejo de reparar essa história que todos sabem como se encerra. } \\
\text { O1/O4/2004 } \\
\text { DESCULPEM-ME!!! } \\
\text { FIZ MELDA. FUI SALVAR UM POST E ACABEI APAGANDO OS POSTS QUE } \\
\text { ESTAVAM AQUI. } \\
\text { VOU PEDIR AJUDA À NINA. DESCULPA NININHA!! APAGUEI SEM QUERER } \\
\text { SEUS POSTS. } \\
\text { ACHO QUE PRECISO FAZER UM CURSO DE BLOG NEM QUE SEJA POR } \\
\text { BY SUZE }\end{array}$ \\
\hline
\end{tabular}

